\title{
을
}

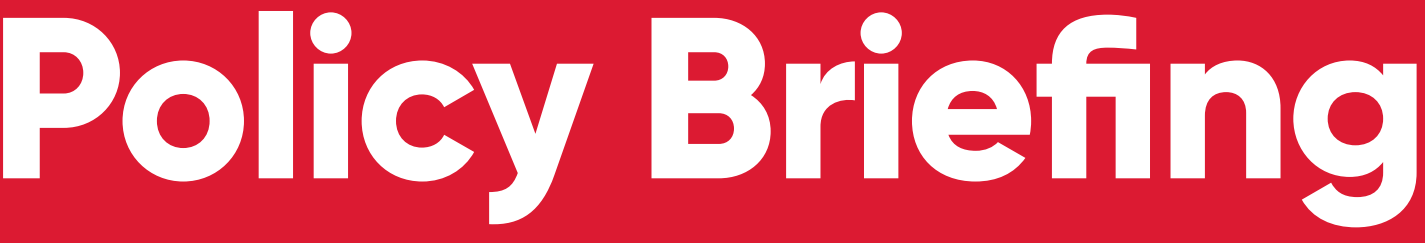

\section{Youth, Land and Rural Livelihoods in Africa}

Rural economic transformations in Africa are generating new opportunities to engage with agricultural value chains. However, many young people are said to be locked out of such opportunities because of limited access to farmland, which pushes them out of agriculture and rural areas, and/or hinders their autonomy. This framing of the 'land problem' imperfectly reflects rural young people's livelihoods in much of sub-Saharan Africa, and therefore does not provide a solid basis for policy. Policy-relevant discussions must consider the diversity of rural contexts, broader land dynamics and more nuanced depictions of youth engagement with the rural economy.

\section{Key messages}

- Many young people farm and will continue to be involved in agriculture as the rural population grows. However, it is harder than ever for new generations of young rural Africans to access land, particularly in densely populated areas.

- Increasing demand for land - from both locals and outsiders exacerbates scarcity, but also stimulates sales and rental markets, the latter being increasingly important mechanisms for young people to access farmland.

- Land commodification is often accompanied by increased commercial investment in agriculture and diversity in the rural non-farm sector. These changes may broaden livelihood options for some young people.

- As market-enabled land acquisition is becoming less associated with formal household formation, surveys that focus on household landholdings may systematically miss information about land that is farmed by individual household dependents. 


\section{Land and rural transformation}

Economic, social and political relations around land in rural sub-Saharan Africa are in flux. The rural population is projected to grow by one third between now and 2050, which will put additional pressure on available land. Traditional tenure regimes are becoming less important as land is increasingly accessed through markets (i.e. the commodification of rural land). The distribution of farm size is changing, with medium-scale farms (5-100 hectares) becoming increasingly important in many areas, and larger commercial investments also taking place. These interlinked developments are playing out in the context of climate change and competing visions of the future of African agriculture: technology-enhanced and market-oriented 'sustainable' productivity enhancement on the one hand, and food sovereignty and 'regenerative agriculture' on the other.

Over the past decade, agriculture has been central to the increasingly prominent policy discussion of youth in sub-Saharan Africa. For agro-optimists, growing national and regional markets, and high-value international value chains, present real opportunities for entrepreneurial young people to both earn a living and transform African smallholder agriculture. Armed with planning skills, digital technology linked to big data, access to financial services and appropriate mechanisation, the agro-optimists argue that young people will be well placed to lead the shift to 'farming as a business'.

In contrast, while acknowledging that agriculture will continue to provide employment for many rural young people for years to come, agro-pessimists highlight the very significant challenges posed by

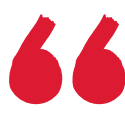
An overly simplified rendering of the 'land problem' African youth face is not useful for policy guidance.

poor infrastructure, underperforming support institutions (e.g. in research and extension services) and biophysical diversity. From this perspective, while young people will continue to be involved in agriculture because there are few other options, there is uncertainty about the scope for obtaining decent livelihoods from agriculture alone.

It is important to note that from both agrooptimist and agro-pessimist perspectives, access to farmland will continue to be critically important to millions of rural young people as they seek to build livelihoods and transition to adulthood.

\section{Many young people farm}

Between 2017 and 2020, a consortium led by the Institute of Development Studies (IDS), with funding from the International Fund for Agricultural Development (IFAD), undertook research on young people's engagement with the rural economy in sub-Saharan Africa. The research included analysis of nationally representative household surveys from Burkina Faso, Ethiopia, Niger, Nigeria, Tanzania, Uganda and Zambia. In addition, qualitative fieldwork was conducted in Côte d'Ivoire, Ethiopia, Nigeria and Uganda. Across a total of 16 sites, the qualitative work included 64 group discussions, 416 individual interviews with young people (aged 15-33) and 92 interviews with adults.

In line with other research, this project's quantitative and qualitative analyses highlight the fact that, across a variety of contexts, a high proportion of economically active young women and men engage in agriculture through self-employment, and waged and/or unpaid domestic labour. Many combine farming with non-farm income-generating activities. Of the young people interviewed during the field research, 70 per cent reported some ownaccount farming (a much higher percentage than indicated by household survey data).

Three broad patterns of engagement with the rural economy are evident from this research. The first, and generally commonest, includes those who combine own account or family farming with some other type(s) of 
non-farm self-employment and/or wage

labour. The second commonest includes those who do not farm, but only engage in non-farm self-employment and/or wage labour. The third includes those who only farm: this is the least common in all sites.

Some farming by young people takes the form of unpaid family labour. And whether or not they farm, many young people are also involved in domestic labour and caring for parents or elderly relatives, siblings' children or their own young families. One important distinction is between young people who live in their natal household (headed by a parent or older relative) and those who live in an independent household with their spouse or partner. While the broad patterns of activity are similar, those in independent households exercise a greater level of autonomy.

\section{Accessing land - an evolving story}

Nationally representative surveys indicate that average farm sizes differ widely across countries. Nevertheless, within each country, households headed by individuals aged under 30 are associated with smaller farm sizes on average (with the exception of Nigeria, where there is little difference across age groups). However, care must be exercised in interpreting this relationship as evidence of young people's constrained access to land.

Other factors, such as limited access to capital, labour, machinery and/or experience in farming may also partially explain the smaller farm sizes observed among youthheaded households. Even if access to land was unconstrained, these other factors would still be likely to limit the farm size of younger households. Thus, farm size should not be seen as direct and unequivocal evidence that young people's farming activities are constrained because they cannot access land.

Indeed, the case that young people find it increasingly difficult to access land is essentially circumstantial. Increasing rural population density and decreasing likelihood of inheriting land as a young person are often cited as evidence, as is the shrinking proportion of land under customary tenure

\section{We need better evidence about the social and economic trade-offs of alternative land market configurations and farm size distributions.}

regimes. Nationally representative survey evidence from Zambia suggests that, with time, a decreasing proportion of household heads of all ages agree that unallocated land is still available in their area.

However, traditional means of access are clearly still important. In 13 of our 15 qualitative study sites, the commonest way young people accessed land was through family/customary channels. But how well such activities are reflected in survey data - where control of parcels associated with a household is typically mapped to the head and/or spouse - remains unclear. The definitions and relative importance of individual and/or household 'ownership' versus rental or borrowing varied greatly across our qualitative sites, but most young people did report some kind of access.

It is clear that while rental markets are not equally important everywhere, young people are increasingly using them to access land. Paradoxically, given the relatively greater importance of land markets to young people, after controlling for observable measures of land quality, there seem to be higher costs for them to access such markets. Qualitative accounts indicate how difficult it is to cleanly describe the nature of youth participation in rental markets, or assert the impacts (positive and/or negative) of land commodification on young people's farming and livelihoods.

Changes in land institutions and farm structure are co-evolving with off-farm agricultural and non-agricultural economic opportunities. This complicates our understanding of the causal relationship between land and increasingly diversified rural livelihoods. But it is clear that an overly simplified rendering of the 'land problem' African youth face is not useful for policy guidance.

\section{ids.ac.uk}




\section{Policy recommendations}

The focus on youth and agriculture in sub-Saharan Africa is likely to remain strong over the coming years. Given rapidly changing land dynamics, and the importance of land to future generations of young people as they build livelihoods, there will be continued pressure to actively address the youth 'land problem'.

In the light of very high levels of spatial diversity in the factors driving land dynamics and rural transformation, and our still limited understanding of how young women and men negotiate these dynamics, policymakers, youth advocates and development practitioners should:

- Avoid the trap of interpreting the small size of land controlled by youth-headed households as direct evidence of their inability to access adequate land.

- Recognise the overriding importance of spatial diversity and context: in relation to young people and land, there is absolutely no place for one-size-fits-all or blueprint solutions.
- Acknowledge that all modes of land access, from customary tenure regimes to formal rental markets, create winners and losers. Rather than praising or damning particular models on ideological grounds, the challenge is to better understand the social, gender, political and economic trade-offs of alternative market configurations, and how contextdependent policies could mitigate them.

- Invest in new approaches to data collection and analysis that can better monitor the activities and interstitial spaces occupied by young people who are not household heads in the conventional sense. It is likely that many of their economic activities - on and off the farm - are very imperfectly observed using conventional modes of householdbased data collection. There is great scope for exploratory qualitative work to guide new and better sampling frames, and better questions and modes of survey data collection, as well as greater scope for intentional mixed methods.
Institute of Development Studies, Library Road, Brighton, BN1 9RE, United Kingdom +44 (0)1273 606261 ids.ac.uk IDS is a charitable company limited by guarantee and registered in England. Charity Registration Number 306371. Charitable Company Number 877338.

\section{Further reading}

Abay, K. et al. (2020) 'Landscapes of Opportunity: A New Window on Young People's Engagement with the Rural Economy in Sub-Saharan Africa', Journal of Development Studies 57.4: 594-613

Chamberlin, J.; Yeboah, F.K. and Sumberg, J. (2021) 'Young People and Land', in J. Sumberg (ed.), Youth and the Rural Economy in Africa: Hard Work and Hazard, Wallingford: CABI

Ricker-Gilbert, J. and Chamberlin, J. (2018) 'Transaction Costs, Land Rental Markets and Their Impact on Youth Access to Agriculture in Tanzania', Land Economics 94.4: 541-55

Yeboah, F.K.; Jayne, T.; Muyanga, M. and Chamberlin, J. (2019)

Youth Access to Land, Migration and Employment

Opportunities: Evidence from Sub-Saharan Africa, IFAD

Research Series 53, Rome: IFAD
This IDS Policy Briefing was written by Jordan Chamberlin CIMMYT and James Sumberg, IDS and edited by Carol

Smithyes, IDS. It was produced as part of the IFAD-funded research programme Challenges and Opportunities for Rural Youth Employment in Sub-Saharan Africa: A Mixed-Methods Study to Inform Policy and Programmes.

The opinions expressed are those of the authors and do not necessarily reflect the views or policies of IDS or IFAD.

(c) Institute of Development Studies 2021.

(i) (5) This is an Open Access briefing distributed under the terms of the Creative Commons Attribution Non Commercial 4.0 International licence (CC BY-NC), which permits use, distribution and reproduction in any medium, provided the original authors and source are credited, any modifications or adaptations are indicated, and the work is not used for commercial purposes.

ISSN 1479-974X

DOI: 10.19088/IDS.2021.040 